\title{
Freshwater carbon and nutrient cycles revealed through reconstructed population genomes
}

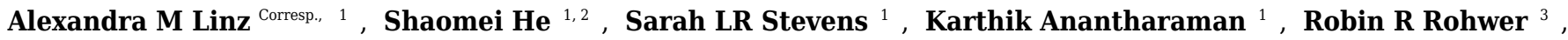 \\ Rex R Malmstrom ${ }^{4}$ ， Stefan Bertilsson ${ }^{5}$, Katherine D McMahon ${ }^{1,6}$ \\ 1 Department of Bacteriology, University of Wisconsin-Madison, Madison, Wisconsin, United States \\ 2 Department of Geoscience, University of Wisconsin-Madison, Madison, Wisconsin, United States \\ 3 Environmental Chemistry and Technology Program, University of Wisconsin-Madison, Madison, Wisconsin, United States \\ 4 Department of Energy Joint Genome Institute, Walnut Creek, California, United States \\ 5 Department of Ecology and Genetics, Limnology and Science for Life Laboratory, Uppsala University, Uppsala, Sweden \\ 6 Department of Civil and Environmental Engineering, University of Wisconsin-Madison, Madison, Wisconsin, United States \\ Corresponding Author: Alexandra M Linz \\ Email address: amlinz@wisc.edu
}

Although microbes mediate much of the biogeochemical cycling in freshwater, the categories of carbon and nutrients currently used in models of freshwater biogeochemical cycling are too broad to be relevant on a microbial scale. One way to improve these models is to incorporate microbial data. Here, we analyze both genes and genomes from three metagenomic time series and propose specific roles for microbial taxa in freshwater biogeochemical cycles. Our metagenomic time series span multiple years and originate from a eutrophic lake (Lake Mendota) and a humic lake (Trout Bog Lake) with contrasting water chemistry. Our analysis highlights the role of polyamines in the nitrogen cycle, the diversity of diazotrophs between lake types, the balance of assimilatory versus dissimilatory sulfate reduction in freshwater, the various associations between types of phototrophy and carbon fixation, and the density and diversity of glycoside hydrolases in freshwater microbes. We also investigated aspects of central metabolism such as hydrogen metabolism, oxidative phosphorylation, methylotrophy, and sugar degradation. Finally, by analyzing the dynamics over time in nitrogen fixation genes and Cyanobacteria genomes, we show that the potential for nitrogen fixation is linked to specific populations in Lake Mendota. This work represents an important step towards incorporating microbial data into ecosystem models and provides a better understanding of how microbes may participate in freshwater biogeochemical cycling. 


\section{Freshwater carbon and nutrient cycles revealed through reconstructed}

\section{2 population genomes}

3 Alexandra M. Linz ${ }^{1}$, Shaomei He ${ }^{1,2}$, Sarah L. R. Stevens ${ }^{1}$, Karthik Anantharaman ${ }^{1}$, Robin R.

4 Rohwer $^{3}$, Rex R. Malmstrom ${ }^{4}$, Stefan Bertilsson ${ }^{5}$, Katherine D. McMahon ${ }^{1,6}$

$5{ }^{1}$ Department of Bacteriology, University of Wisconsin-Madison, ${ }^{2}$ Department of Geoscience,

6 University of Wisconsin-Madison, ${ }^{3}$ University of Wisconsin-Madison Environmental Chemistry

7 and Technology Program, ${ }^{4}$ Department of Energy Joint Genome Institute, ${ }^{5}$ Department of

8 Ecology and Genetics, Limnology and Science for Life Laboratory, Uppsala University,

$9{ }^{6}$ Department of Civil and Environmental Engineering, University of Wisconsin-Madison,

11 *Corresponding author: Alexandra Linz, Department of Bacteriology, University of Wisconsin

121550 Linden Drive Room 5525 Madison, WI 53706, Email: amlinz@,wisc.edu

14 Abstract word count: 217

15 Article word count: 5,177 (including citations and headers)

17 Running title: Nutrient cycles revealed through genomes 


\section{Abstract}

Although microbes mediate much of the biogeochemical cycling in freshwater, the categories of carbon and nutrients currently used in models of freshwater biogeochemical cycling are too broad to be relevant on a microbial scale. One way to improve these models is to incorporate microbial data. Here, we analyze both genes and genomes from three metagenomic time series and propose specific roles for microbial taxa in freshwater biogeochemical cycles. Our metagenomic time series span multiple years and originate from a eutrophic lake (Lake Mendota)

34 and a humic lake (Trout Bog Lake) with contrasting water chemistry. Our analysis highlights the

35 role of polyamines in the nitrogen cycle, the diversity of diazotrophs between lake types, the balance of assimilatory versus dissimilatory sulfate reduction in freshwater, the various

37 associations between types of phototrophy and carbon fixation, and the density and diversity of 38 glycoside hydrolases in freshwater microbes. We also investigated aspects of central metabolism such as hydrogen metabolism, oxidative phosphorylation, methylotrophy, and sugar degradation.

40 Finally, by analyzing the dynamics over time in nitrogen fixation genes and Cyanobacteria 41 genomes, we show that the potential for nitrogen fixation is linked to specific populations in Lake 42 Mendota. This work represents an important step towards incorporating microbial data into ecosystem models and provides a better understanding of how microbes may participate in

44 freshwater biogeochemical cycling. 


\section{Introduction}

Lakes receive nutrients from surrounding terrestrial ecosystems (Williamson et al., 2008),

51 placing lakes as "hotspots" for carbon and nutrient cycling in the landscape (Butman et al., 2015).

52 Approximately half of the carbon received by freshwater ecosystems from the terrestrial landscape

53 is emitted as carbon dioxide (0.2 Pg C/year) or buried in sediments (0.8 Pg C/year) (Cole et al.,

54 2007). Similarly, $20 \%$ of global denitrification is estimated to occur in freshwater, roughly

55 equivalent to the amount of denitrification taking place in soils (22\%) and about a third of the

56 amount occurring in oceans (58\%) (Seitzinger et al., 2006).

Most of this freshwater biogeochemical cycling is performed by microbial communities,

yet the categories in the models and budgets used to study these cycles are too broad to incorporate microbial data. For example, carbon compounds are often classified as labile and recalcitrant

60 (Guillemette \& del Giorgio, 2011), or autochthonous and allochthonous (Jonsson et al., 2001).

61 While some work has been done on microbial responses to these carbon categories (Eiler et al.,

62 2003; Kritzberg et al., 2004), using such broad categorizations masks the complexity of microbial ecophysiology. Incorporating microbially-mediated transformations of specific compounds in freshwater would significantly improve the accuracy and predictive power of biogeochemical cycling models.

However, linking microbial taxa to specific biogeochemical functions is a challenging task. Previous research has investigated substrate use by freshwater taxa in cultured isolates and microscopy fluorescence in situ hybridization coupled to microautoradiography to detect incorporation of labeled substrates in uncultured lineages (Hahn et al., 2012; Salcher, Posch \& Pernthaler, 2013). While these techniques are definitive, they cannot be scaled to investigate many community members simultaneously. Other research has used scalable genomics techniques to 
72 link microbial taxa to predicted biogeochemical functions, generating hypotheses that can be tested

73 using more targeted experiments. Sequencing data has previously been employed to great effect

74 to analyze the distribution of functional marker genes in freshwater (Ramachandran \& Walsh,

75 2015; Peura et al., 2015) and to predict metabolic potential in freshwater genomes (Salcher et al.,

76 2015; Eiler et al., 2016; Hamilton et al., 2017; He et al., 2017; Cabello-Yeves et al., 2018).

77 In this research, we combined insights from both genes and genomes in three freshwater

78 metagenomic time series to link function to taxonomy at the community level. Our metagenomic

79 time series included multiple years of sampling for microbial DNA from two lakes in Wisconsin,

80 USA: Lake Mendota, a large eutrophic lake, and Trout Bog Lake, a small humic lake. Lake

81 Mendota and Trout Bog Lake are ideal sites for comparative time series metagenomics because of

82 their contrasting limnological attributes and their history of extensive environmental sampling by

83 the North Temperate Lakes - Long Term Ecological Research program (NTL-LTER,

84 http://lter.limnology.wisc.edu) (Table 1, Table S1). They have also been the subjects of many prior

85 efforts to document and understand freshwater bacterial community diversity and dynamics (Shade

86 et al., 2007; Linz et al., 2017; Hall et al., 2017). We described both predicted pathways in

87 metagenome-assembled genomes (MAGs) and the distributions of functional marker genes to

88 provide a comprehensive overview of microbially-mediated biogeochemical cycling in these two

89 contrasting freshwater lakes.

90 Throughout this paper, we highlight several functional categories with particularly

91 interesting results. We discuss differences in the identity and diversity of potential nitrogen fixing

92 bacteria in Trout Bog vs. Mendota, as well as the high prevalence of genes related to polyamines,

93 which are proposed to be an important component of the dissolved organic nitrogen pool. We

94 observed that assimilatory sulfate reduction pathways were encoded more frequently than 
95 dissimilatory sulfate reduction pathways, in contrast to what is thought to be the case in marine

96 systems. We split the broader category of primary production into different types of phototrophy,

97 including photosynthesis performed by Cyanobacteria, green sulfur bacteria, and aerobic

98 anoxygenic phototrophs, and analyzed their associated carbon fixation pathways (when present).

99 Using annotations of carbohydrate-active enzymes, we compared the potential for complex carbon

100 degradation and describe significant differences in the coding density and diversity of these

101 encoded enzymes between lakes. To compare more basic properties of freshwater microbes, we

102 assessed differences between lakes in central microbial metabolisms such as hydrogen

103 metabolism, oxidative phosphorylation, methylotrophy, and degradation of low molecular weight

104 carbon. Finally, we show how trends over time in the abundances of both nitrogen fixation marker

105 genes and Cyanobacteria MAGs likely encoding nitrogen fixation were highly correlated,

106 demonstrating how genomic data can reveal dynamics in both functions and taxa.

\section{Methods}

108 Sampling

109 Samples were collected from Lake Mendota and Trout Bog Lake as previously described

110 (Bendall et al., 2016). Briefly, integrated samples of the water column were collected during the

111 ice-free periods of 2007-2009 in Trout Bog and 2008-2012 in Mendota. In Mendota, the top 12

112 meters of the water column were sampled, approximating the epilimnion (upper, oxygenated, and

113 warm thermal layer). The epilimnion and hypolimnion (bottom, anoxic, and cold thermal layer) of

114 Trout Bog were sampled separately at depths determined by measuring temperature and dissolved

115 oxygen concentrations. The sampling depths were most often 0-2 meters for the epilimnion and

$1162-7$ meters for the hypolimnion. DNA was collected by filtering $150 \mathrm{~mL}$ of the integrated water

117 samples on $0.2-\mu \mathrm{m}$ pore size polyethersulfone Supor filters (Pall Corp., Port Washington, NY, 
118 USA). Filters were stored at -80C until extraction using the FastDNA Spin Kit (MP Biomedicals,

119 Burlingame, CA, USA) with minor modifications (Shade et al., 2007).

120 Sequencing

121 As previously described (Bendall et al., 2016; Roux et al., 2017), metagenomic sequencing

122 was performed by the Department of Energy Joint Genome Institute (DOE JGI) (Walnut Creek,

123 CA, USA). A total of 94 samples collected over five years were sequenced for Mendota, while 47

124 metagenomes collected over three years were sequenced for each layer in Trout Bog (Table S2).

125 Samples were sequenced on the Illumina HiSeq 2500 platform (Illumina, San Diego, CA, USA),

126 except for four libraries (two from each layer of Trout Bog) that were sequenced using the Illumina

127 TruSeq protocol on the Illumina GAIIx platform; all samples were sequenced using paired ends

128 with read lengths of 150 base pairs (Data S1). Paired-end sequencing reads were merged with

129 FLASH v1.0.3 with a mismatch value of less than 0.25 and a minimum of 10 overlapping bases

130 (Magooc \& Salzberg, 2011). 16S rRNA gene amplicon sequencing was also performed on samples

131 collected with the same method over the same time periods. These datasets are available under

132 DOE JGI project IDs 1078703 and 1018581 for Trout Bog and Mendota, respectively. Samples

133 from Trout Bog were sequenced on the 454 GS FLX-Titanium platform (Roche 454, Branford,

134 CT, USA) targeting the V8 hypervariable region (primer 1392R: ACGGGCGGTGTGTRC)

135 (Engelbrektson et al., 2010), and sequences were trimmed to 324 base pairs using VSEARCH

136 (v2.3.4) (Rognes et al., 2016). Samples from Mendota were sequenced on an Illumina MiSeq, and

137 the V4 region was targeted using paired-end sequencing (primers 525F:

138 GTGCCAGCMGCCGCGGTAA and 806R: GGACTACHVGGGTWTCTAAT) (Caporaso et al.,

139 2012). Both datasets were trimmed based on alignment quality and chimera checking using mothur

140 v.1.39.5 (Schloss et al., 2009). Unclustered, unique sequences were classified using a custom 
141 database of freshwater 16S rRNA gene sequences (Newton et al., 2011) and the Greengenes

142 database (DeSantis et al., 2006) with the classification pipeline TaxAss (Rohwer et al., 2018).

143 Assembly and Binning

144 To recover MAGs, metagenomic reads from the same sampling sites (Mendota's

145 epilimnion, Trout Bog's epilimnion, and Trout Bog's hypolimnion) were pooled (Table S2) and

146 then assembled as previously described (Bendall et al., 2016; Roux et al., 2017). In metagenomes

147 from Trout Bog, this assembly was performed using SOAPdenovo2 at various k-mer sizes (Luo et

148 al., 2012), and the resulting contigs were combined using Minimus (Sommer et al., 2007). In Lake

149 Mendota, merged reads were assembled using Ray v2.2.0 with a single k-mer size (Boisvert et al.,

150 2012). Contigs from the combined assemblies were binned using MetaBAT (-veryspecific settings,

151 minimum bin size of $20 \mathrm{~kb}$, and minimum contig size of 2.5kb) (Kang et al., 2015), and reads from

152 individual metagenomes were mapped to the assembled contigs using the Burrows-Wheeler

153 Aligner $(\geq 95 \%$ sequence identity, $\mathrm{n}=0.05)(\mathrm{Li} \&$ Durbin, 2010), which allowed time-series

154 resolved binning (Table S2). DOE JGI's Integrated Microbial Genome (IMG) database tool

155 (https://img.jgi.doe.gov/mer/) (Markowitz et al., 2012) was used for gene prediction and

156 annotation. Annotated MAGs can be retrieved directly from the IMG database and JGI's Genome

157 Portal using the IMG Genome ID provided (also known as IMG Taxon ID). MAG completeness

158 and contamination/redundancy was estimated based on the presence of a core set of genes with

159 CheckM (Rinke et al., 2013; Parks et al., 2015), and MAGs were taxonomically classified using

160 Phylosift (Darling et al., 2014) or the phylogeny-based "guilt by association" method (Hamilton

161 et al., 2017). As recommended by Bowers et al., 2017, only MAGs that were at least

162 approximately 50\% complete with less than $10 \%$ estimated contamination/redundancy (meeting 
163 the MIMARKS definition of a medium or high quality MAG) (Bowers et al., 2017) were included

164 in the study.

165 A total of 193 medium to high quality bacterial MAGs were recovered from the three

166 combined time series metagenomes in Trout Bog and Mendota: 99 from Mendota, 31 from Trout

167 Bog's epilimnion, and 63 from Trout Bog's hypolimnion (Data S2). These population genomes

168 ranged in estimated completeness from 50 to $99 \%$ based on CheckM estimates. Several MAGs

169 from Trout Bog's epilimnion and hypolimnion appeared to belong to the same population based

170 on average nucleotide identities greater than $99 \%$ calculated using DOE JGI's ANI calculator

171 (Data S3) (Varghese et al., 2015). This is likely because assembly and binning were carried out

172 separately for each thermal layer, even though some populations were present throughout the water

173 column.

\section{Functional Marker Gene Analysis}

175 To analyze functional marker genes in the unassembled, unpooled metagenomes, we used

176 a curated database of reference protein sequences (Data S4) (Anantharaman et al., 2016) and

177 identified open reading frames (ORFs) in our unassembled metagenomic time series using

178 Prodigal (Hyatt et al., 2010). This analysis was conducted on merged reads. The protein sequences

179 and ORFs were compared using BLASTx (Camacho et al., 2009) with a cutoff of 30\% identity.

180 Read abundance was normalized by metagenome size for plotting. We chose to perform this

181 analysis because gene content in unassembled metagenomes is likely more quantitative and more

182 representative of the entire microbial community than gene content in the MAGs, due to limitations

183 of assembly and binning algorithms.

184 These comparisons were run between the epilimnia of Trout Bog and Mendota, and

185 between the epilimnion and hypolimnion of Trout Bog. We did not compare Mendota's epilimnion 
186 to Trout Bog's hypolimnion, as the multitude of factors differing between these two sites make

187 this comparison illogical. We aggregated marker genes by function (as several marker genes from

188 a phylogenetic range were included in the database for each type of function) and tested for

189 significant differences in distribution between lakes and layers using a Wilcoxon rank sum test in

190 R with a Bonferroni correction for multiple pairwise testing.

191 Pathway Prediction

192 Pathways were analyzed by exporting IMG's functional annotations for the MAGs,

193 including KEGG, COG, PFAM, and TIGRFAM annotations and mapped to pathways in the

194 KEGG and MetaCyc databases as previously described (He et al., 2017). To score presence, a

195 pathway needed at least $50 \%$ of the required enzymes encoded by genes in a MAG and if there

196 were steps unique to a pathway, at least one gene encoding each unique step. Putative pathway

197 presen was aggregated by lake and phylum in order to link potential functions identified in the

198 metagenomes to taxonomic groups that may perform those functions in each lake. Glycoside

199 hydrolases were identified using dbCAN2's implementation of HMMER (Zhang et al., 2018).

200 Nitrogen usage in amino acids was calculated by taking the average number of nitrogen atoms in

201 translated ORF sequences across each MAG.

202 Data formatting and plotting was performed in R (R Core Team (2017). R: A language and 203 environment for statistical computing. R Foundation for Statistical Computing, Vienna, Austria.

204 URL https://www.R-project.org/.) using the following packages: ggplot2 (H. Wickham. ggplot2:

205 Elegant Graphics for Data Analysis. Springer-Verlag New York, 2009.), cowplot (Claus O. Wilke 206 (2017). cowplot: Streamlined Plot Theme and Plot Annotations for 'ggplot2'. R package version

207 0.9.2. https://CRAN.R-project.org/package=cowplot), reshape2 (Hadley Wickham (2007).

208 Reshaping Data with the reshape Package. Journal of Statistical Software, 21(12), 1-20. URL 
209 http://www.jstatsoft.org/v21/i12/.), and APE (Paradis E., Claude J. \& Strimmer K. 2004. APE:

210 analyses of phylogenetics and evolution in R language. Bioinformatics 20: 289-290.). The datasets,

211 scripts, and intermediate files used to predict pathway presence and absence are available at

$212<$ https://github.com/McMahonLab/MAGstravaganza $>$. Any future updates or refinements to this

213 dataset will be available at this link.

\section{Results/Discussion}

\section{Community Functional Marker Gene Analysis}

Due to the contrasting water chemistry of Mendota and Trout Bog (Table 1, Table S1), we expected that microbial metabolisms would differ between lakes, and that these differences would be reflected in metagenomic gene content. To assess the potential for differing microbial metabolisms by lake, we tested whether functional marker genes identified in the unassembled merged metagenomic reads appeared more frequently in one lake or layer compared to the others.

Many functional markers were found to be significantly more abundant in specific sites; more will 222 be reported in each of the following sections (Figure 1, Table S3). The recovered MAGs represent a diverse set of genomes assigned to taxonomic groups typically observed in freshwater (Figure 224 S2).

\section{Overview of the MAGs Dataset}

To identify the phylogenetic affiliations of the microbes carrying marker genes and the cooccurrences of key marker genes within the same population genomes, we used metagenomeassembled genomes (MAGs) from each metagenomic time series to predict metabolic pathways based on genomic content. To assess the diversity of our MAGs, we constructed an approximate maximum likelihood tree of all the MAGs in FastTree (Price, Dehal \& Arkin, 2010) using whole 231 genome alignments (Figure S1). The tree is not intended to infer detailed evolutionary history, but 
232 to provide an overall picture of similarity between genomes. MAGs recovered are a diverse set of

233 genomes assigned to taxa typically observed in freshwater (Figure S2).

234 We also compared 16S rRNA gene amplicon sequencing data from the same timeframe as

235 the metagenomes to confirm that the microbial community composition for these lakes and years

236 was not "abnormal" compared to previous published studies (Figure S3). The observed taxonomic

237 compositions were consistent with other 16S-based studies carried out on these lakes (Linz et al.,

238 2017; Hall et al., 2017) and with freshwater bacterial community compositions in general (Newton

239 et al., 2011).

240 Nitrogen Cycling

241 Nitrogen availability is an important factor structuring freshwater microbial communities.

242 It is often a determining factor in a lake's trophic status and a risk factor for the development of

243 toxic cyanobacterial blooms (Smith, 2003; Beversdorf, Miller \& McMahon, 2013). Because of the

244 significance of nitrogen in freshwater, we analyzed nitrogen-related marker genes and identified

245 MAGs containing characteristic nitrogen cycling pathways and discovered significant differences

246 in the abundances of marker genes, along with differences in phylogenetic affiliations of the MAGs

247 containing these pathways.

248 Genes encoding nitrogenase, the key enzyme in nitrogen fixation, were observed most

249 frequently in metagenomes from Trout Bog's hypolimnion, followed by Trout Bog's epilimnion,

250 and lastly by Mendota's epilimnion (Figure 1, Table S3). We analyzed MAGs predicted to fix

251 nitrogen and found differences in the identities of putative diazotrophs between the two ecosystems

252 (Figure 2, Figure S1, Data S5). In Mendota, two thirds of MAGs encoding the nitrogen fixation

253 pathway were classified as Cyanobacteria, while the other third was assigned to

254 Betaproteobacteria and Gammaproteobacteria. Although not all Cyanobacteria fix nitrogen, 
255 previous studies of nitrogen fixation in Mendota have reported a strong correlation between this

256 pathway and the cyanobacterium affiliated with Aphanizomenon (Beversdorf, Miller \& McMahon,

257 2013). MAGs containing genes encoding nitrogen fixation were more phylogenetically diverse in

258 Trout Bog and included Deltaproteobacteria, Gammaproteobacteria, Epsilonproteobacteria,

259 Acidobacteria, Verrucomicrobia, Chlorobi, and Bacteroidetes. The higher diversity of diazotrophs

260 in Trout Bog compared to Mendota suggests that nitrogen fixation may be a more advantageous

261 trait in humic lakes than in eutrophic lakes.

262 We noted a high frequency of genes related to polyamine biosynthesis and degradation in

263 our MAGs. We found that $94 \%$ of MAGs encoded pathways for polyamine synthesis, and $87 \%$

264 encoded pathways for polyamine degradation. These pathways were predicted in diverse MAGs

265 from both lakes, including Actinobacteria as previously observed (Ghylin et al., 2014; Hamilton

266 et al., 2017). While there is some evidence for the importance of polyamines in aquatic systems

267 (Mou et al., 2011), the ecological roles of these compounds in freshwater are not fully resolved.

268 Polyamines are known to play a critical but poorly understood role in bacterial metabolism

269 (Igarashi \& Kashiwagi, 1999), and the exchange of these nitrogen compounds between populations

270 may be a factor structuring freshwater microbial communities. Polyamines can also result from

271 the decomposition of amino acids, so higher trophic levels such as fish or zooplankton may

272 represent an additional polyamine source (Al Bulushi et al., 2009). The frequent appearance of

273 polyamine-related pathways in our MAGs lends support to the hypothesis that these compounds

274 are important but largely unrecognized parts of the dissolved organic nitrogen and carbon pool in 275 freshwater.

276 We analyzed genes for denitrification, including reductases for nitrous oxide, nitrite, and

277 nitrate. Denitrification genes were observed most frequently in Trout Bog's hypolimnion, with the 
278 exception of nitrous oxide reductase, which was found more frequently in Mendota. Genes

279 encoding urease were not identified more frequently in any site. Denitrification and urea

280 degradation pathways were predicted in similar proportions of MAGs from both lakes.

\section{Sulfur Cycling}

Sulfur is another essential element in freshwater that is cycled between oxidized and

283 reduced forms by microbes. Our marker gene analysis demonstrated that genes encoding

284 sulfide:quinone reductase (for sulfide oxidation) and the sox pathway (for thiosulfate oxidation)

285 were significantly more abundant in Trout Bog compared to Mendota, with no significant

286 differences between the layers of Trout Bog (Figure 1, Table S3). Genes encoding sulfite

287 reductases were the least abundant sulfur cycling marker genes in all sites. Dissimilatory sulfite

288 reductase was observed only in MAGs from Trout Bog, especially those classified as Chlorobiales.

289 Because this enzyme is thought to operate in reverse in green sulfur-oxidizing phototrophs such as

290 Chlorobiales (Holkenbrink et al., 2011), this may indicate an oxidation process rather than a

291 reductive sulfur pathway. Sulfur oxidation pathways were observed in MAGs classified as

292 Betaproteobacteria from both lakes and Epsilonproteobacteria in Trout Bog's hypolimnion.

293 Assimilatory sulfate reduction was overall the most common sulfur-related pathway identified in

294 the MAGs (Figure 2, Data S5).

295 Assimilatory sulfate reduction was observed more frequently than dissimilatory sulfate

296 reduction; this suggests that sulfate is more commonly used for biosynthesis, while reduced forms

297 of sulfur are used as electron donors for energy mobilization in these populations. This is in

298 contrast to marine systems, where sulfate reduction holds a central role as an energy source for

299 organotrophic energy acquisition (Bowles et al., 2014), although sulfate reduction could also be 300 occurring in Mendota's hypolimnion. 
302 Phototrophy

Primary production (the coupling of photosynthesis and carbon fixation) is a critical component of the freshwater carbon cycle. To identify differences in routes of primary production between freshwater environments, we compared marker genes for carbon fixation across sites. RuBisCO (ribulose-1,5-bisphosphate carboxylase/oxygenase), the marker gene for carbon fixation via the Calvin-Benson-Bassham (CBB) pathway, was most frequently observed in Trout Bog's epilimnion (Figure 1, Table S3).

We assessed the MAGs for photoautotrophy, expecting to find differences between our two study sites based on the observed contrasts in the functional marker gene analysis (Figure 2,

311 Data S5). In Mendota, the majority of MAGs encoding phototrophic pathways were classified as

312 Cyanobacteria. These MAGs contained genes encoding enzymes in the CBB pathway. In Trout

313 Bog, most MAGs encoding phototrophy were classified as Chlorobium clathratiforme, a species

314 of Chlorobiales widespread in humic lakes (Karhunen et al., 2013). The Chlorobiales MAGs in

315 Trout Bog contained genes encoding citrate lyase and other key enzymes in the reductive 316 tricarboxylic acid (TCA) cycle, an alternative carbon fixation method commonly found in green 317 sulfur bacteria such as Chlorobi (Kanao et al., 2002; Tang \& Blankenship, 2010). Although we 318 found genes annotated as the RuBisCO large subunit $(r b c L)$ in some of the Chlorobiales MAGs,

319 the reductive TCA cycle is the only carbon fixation pathway known to be active in cultured 320 representatives of Chlorobiales. Homologs of $r b c L$ have been previously identified in isolates of 321 Chlorobium, and were associated with sulfur metabolism and oxidative stress (Hanson \& Tabita, 322 2001). Given this information, it seems likely that this $r b c L$ homolog encodes a function other than 323 carbon fixation in our Chlorobiales MAGs. MAGs affiliated with Cyanobacteria in Mendota and 
324 Chlorobi in Trout Bog also possessed genes encoding diazotrophy, providing a link between

325 carbon and nitrogen fixation. As both Chlorobi and Cyanobacteria are often abundant members

326 of freshwater communities (Eiler \& Bertilsson, 2004; Peura et al., 2012), their fixation capabilities

327 may be relevant even at the ecosystem scale.

328 The potential for photoheterotrophy via the aerobic anoxygenic phototrophic (AAP)

329 pathway was identified in several MAGs from all lake environments, especially from epilimnia,

330 based on the presence of genes annotated as $\operatorname{pufABCLMX}$, $p u h A$, and $p u c A B$ encoding the core

331 reaction center RC-LH1 (Martinez-Garcia et al., 2012b). Betaproteobacteria and

332 Gammaproteobacteria, particularly MAGs classified as Burkholderiales (including PnecC, LD28,

333 and Zwartia alpina), most often contained these genes, although they were not broadly shared

334 across the phylum (Figure 2). As AAP has previously been associated with freshwater

335 Proteobacteria (Martinez-Garcia et al., 2012b), these results are not surprising. However, an

336 Acidobacteria MAG from the Trout Bog epilimnion also contained genes suggesting AAP, which

337 to our knowledge has not previously been found in this phylum.

338 Another form of photoheterotrophy previously identified in freshwater is the use of light-

339 activated proteins such as rhodopsins (Martinez-Garcia et al., 2012b). We observed genes

340 encoding rhodopsins in MAGs from each lake environment, but more frequently in Actinobacteria

341 and Bacteroidetes MAGs from Mendota (Figure 2). Trout Bog, especially the hypolimnion,

342 harbored fewer and less diverse MAGs encoding rhodopsins than those from Mendota.

343 Glycoside Hydrolases

344 Degradation of high-complexity, recalcitrant carbon compounds requires specialized

345 enzymes, but wide availability of these carbon compounds can make complex carbon degradation

346 an advantageous trait. One way to predict the ability to degrade high-complexity carbon in 
347 microbial populations is by identifying genes annotated as glycoside hydrolases (GHs), which

348 encode enzymes that break the glycosidic bonds found in complex carbohydrates. However, it is

349 important to keep in mind that GHs can also play structural roles in microbial cells in addition to

350 the degradation of complex carbon substrates (Henrissat \& Davies, 1997). A previous study of

351 Verrucomicrobia MAGs from our dataset found that the profiles of GHs differed between Mendota

352 and Trout Bog, potentially reflecting the differences in available carbon sources (He et al., 2017).

353 We expanded this analysis of glycoside hydrolases to all of the MAGs in our dataset to identify

354 differences in how populations from our two study sites degrade complex carbohydrates.

355 We calculated the coding density of GHs, defined as the percentage of coding regions in a

356 MAG annotated as a GH to identify differences in carbon metabolism between MAGs from

357 different lake environments (Figure 3, Data S6). Our GH coding density metric was significantly

358 correlated with the diversity of GHs identified $\left(\mathrm{r}^{2}=0.92, \mathrm{p}<2.2 \times 10^{-16}\right)$, which is an indicator of

359 the number of substrates an organism can utilize. The MAGs with the highest GH coding densities

360 were classified as Bacteroidales, Ignavibacteriales, Sphingobacteriales, and Verrucomicrobiales

361 from Trout Bog's hypolimnion. Two of these orders, Sphingobacteriales and Verrucomicrobiales,

362 also contained MAGs with high GH coding densities in Mendota and Trout Bog's epilimnion.

363 There were several additional orders with high GH coding density that were unique to Mendota,

364 including Mycoplasmatales (Tenericutes), Cytophagales (Bacteroidetes), Planctomycetales

365 (Planctomycetes), and Puniceicoccales (Verrucomicrobia). Members of Verrucomicrobia have

366 been previously identified as potential polysaccharide degraders in freshwater, although our

367 coding densities for this phylum are higher than others reported (Martinez-Garcia et al., 2012a).

368 This may be due to differences in trophic status between our lakes and those previously studied,

369 or it may be that MAGs capture more pan-genomic content than isolate or single amplified 
370 genomes. In concordance with their ability to hydrolytically degrade biopolymers to sugars, MAGs

371 with high GH coding densities also contained putative degradation pathways for a variety of sugars

372 (Figure 2). The increased diversity of these genes found in Trout Bog's hypolimnion compared to

373 our other study sites suggests differing diversity and complexity of the available organic carbon.

\section{Central Metabolism and Simple Carbon Degradation}

375

376

377

378

379

380

381

382

383

384

385

386

387

388

389

390

391

Freshwater microbes are exposed to a great variety of low-complexity carbon sources such as carbohydrates, carboxylic acids, and single-carbon (C1) compounds. The central metabolic pathways shared by most living cells are often an entry point for the least complex carbon compounds. Therefore, the specific routing of central metabolism predicted in our MAGs may reveal how low complexity carbon compounds are used within freshwater populations.

We investigated the types of cytochrome oxidases encoded in our MAGs to compare oxidative phosphorylation between lakes and layers (Figure 2, Data S5). Cytochrome c oxidases, both aa3- and cbb3-type, were widespread in all three lake environments and frequently cooccurred within MAGs. aa3-type cytochromes are associated with high oxygen concentrations, while cbb3-type cytochromes are associated with low oxygen concentrations (Gong et al., 2018). The presence of genes encoding both types suggests the flexibility to operate under a range of oxygen concentrations.

Similarly, hydrogen metabolism can influence and be influenced by other aspects of nutrient usage. Iron-only hydrogenases were found primarily in MAGs from Trout Bog's hypolimnion (Figure 2, Table S3), consistent with their previously identified presence in anaerobic, often fermentative bacteria (Peters et al., 2015). Group 3 [Ni-Fe] hydrogenases were identified in MAGs belonging to Cyanobacteria and Chlorobiales in both lakes. This finding is 
392 consistent with the proposed function of Group 3d, which is to remove excess electrons produced

393 by photosynthesis (Peters et al., 2015).

394 Low molecular weight carbohydrates may be derived either from autochthonous (such as

395 algae) or allochthonous (such as terrestrial plants) sources (Giroldo, Augusto \& Vieira, 2005;

396 Ramanan et al., 2015). The pathway for mannose degradation was encoded in many MAGs from

397 all three sites (Figure 2, Data S5). Predicted pathways for rhamnose, fucose, and galactose

398 degradation were often found within the same MAGs (including members of Planctomycetes and

399 Verrucomicrobia from Mendota, and members of Bacteroidetes, Ignavibacteria, and

400 Verrucomicrobia from Trout Bog). Xylose is a freshwater sugar which has already been proposed

401 as a potential carbon source for streamlined Actinobacteria (Ghylin et al., 2014). We confirmed

402 this in our MAGs and also identified Bacteroidetes, Planctomycetes, and Verrucomicrobia from

403 Lake Mendota and Bacteroidetes and Verrucomicrobia from Trout Bog as additional potential

404 xylose degraders. Genes for the degradation of glycolate, an acid produced by algae and consumed

405 by heterotrophic bacteria (Paver \& Kent, 2017), were identified in Cyanobacteria and

406 Betaproteobacteria MAGs from Mendota and in Acidobacteria, Verrucomicrobia, Alpha-, Beta-

407 , Gamma-, and Epsilonproteobacteria MAGs from Trout Bog. The pathways predicted in our

408 MAGs may inform us about which low molecular weight compounds are important carbon

409 substrates in freshwater.

410 Methylotrophy, the ability to grow solely on $\mathrm{C} 1$ compounds such as methane or methanol,

411 was predicted in MAGs from both Trout Bog and Mendota. Putative pathways for methanol and

412 methylamine degradation were found in MAGs classified as Methylophilales (now merged with

413 Nitrosomonadales (Boden, Hutt \& Rae, 2017)), while Methylococcales MAGs were potential

414 methane degraders based on the presence of genes encoding methane monooxygenase. 
415 Methylococcales MAGs from Trout Bog also encoded the pathway for nitrogen fixation, consistent

416 with reports of nitrogen fixation in cultured isolates of this taxon (Bowman, Sly \& Stackebrandt,

417 1995). Methylotrophy in cultured freshwater isolates from Methylococcales and Nitrosomonadales

418 is well-documented (Kalyuzhnaya et al., 2011; Salcher et al., 2015). We also found predicted

419 pathways for methanol degradation in MAGs classified as Burkholderiales and Rhizobiales in

420 Trout Bog. Methylotrophy has been identified in members of Rhizobiales, such as

421 Methylobacterium and Methylocystaceae, and in Burkholderiales, including Methylibium (Auman

422 et al., 2000; Chistoserdova et al., 2003; Kane et al., 2007). Our MAGs may represent populations

423 related to these known methylotrophs.

424 Using MAGs to track population abundances over time

Because our metagenomes comprise a time series, we can investigate potential changes in

function over time using our MAGs and functional marker genes. We analyzed nitrogen fixation

over time in Cyanobacteria, known to be highly variable over time in Mendota. We found that in

each year, one Cyanobacteria MAG was substantially more abundant (based on read coverage)

than the rest; this single MAG was plotted for each year Mendota (Figure 4, A-E). We compared

read coverage-based abundance of the dominant Cyanobacteria MAG to the normalized number

of BLAST hits in the metagenomes from abundant functional marker genes encoding nitrogenase subunits (TIGR1282 (nifD), TIGR1286 (nifK specific for molybdenum-iron nitrogenase), and

TIGR1287 (nifH, common among different types of nitrogenases)) (Figure 4, F-J). As expected,

434 we detected significant correlations $(\mathrm{p}<0.05)$ between MAG abundance and nitrogen fixation marker genes in 2008, 2011, and 2012. In these years, the dominant Cyanobacteria MAGs were

436 predicted to fix nitrogen based on gene content, while the dominant MAGs in 2009 and 2010 were

437 not predicted to fix nitrogen. In agreement with this, the number of hits for the nitrogenase marker 
438 genes were an order of magnitude lower in 2009 and 2010 compared to 2008 and 2012. While

439 genome incompleteness precludes us from concluding that the potential for nitrogen fixation in

440 Mendota was lower in 2009 and 2010 because the dominant Cyanobacteria populations were not

441 diazotrophic, it does suggest a strong link between Cyanobacteria dynamics and nitrogen fixation

442 in this ecosystem (Beversdorf, Miller \& McMahon, 2013). This could also have important

443 implications for cyanotoxin production, since nitrogen stress has been linked to toxin production

444 (Beversdorf et al., 2015).

445 Conclusions

Our analysis of functional marker genes indicated potentially significant difference in

447 microbial biogeochemical cycling between Mendota's epilimnion, Trout Bog's epilimnion, and

448 Trout Bog's hypolimnion. We next used MAGs from multi-year metagenomic time series to

449 propose specific roles in freshwater biogeochemical cycles for microbial taxa. In the nitrogen

450 cycle, we predicted many pathways for the degradation and biosynthesis of polyamines, consistent

451 with their hypothesized role in the dissolved organic nitrogen pool. We observed an association

452 between nitrogen fixation and Cyanobacteria in Mendota, but observed a greater diversity of 453 putative diazotrophs in Trout Bog. Assimilatory sulfate reduction pathways were predicted more

454 frequently that dissimilatory sulfate reduction pathways, suggesting a bias towards using sulfate

455 for biosynthesis. We identified several types of phototrophy, which in some but not all genomes 456 co-occurred with carbon fixation via the Calvin Cycle or the reductive TCA cycle. We found the 457 greatest diversity and density of glycoside hydrolases in MAGs from Trout Bog's hypolimnion, 458 suggesting a greater potential to degrade recalcitrant carbon in this region. Our combination of 459 functional marker gene analysis and MAG pathway prediction provides insight into the complex 
460 metabolisms underpinning freshwater communities and how microbial processes scale to

461 ecosystem functions.

462 We anticipate that this dataset will be a valuable community resource for other freshwater

463 microbial ecologists to mine and incorporate into comparative studies across lakes around the

464 world. As such, all data is publicly available at <

465 https://github.com/McMahonLab/MAGstravaganza >. The results of this study can be used to

466 guide efforts to build microbially-resolved models of freshwater carbon and nutrient cycles with

467 better predictive power.

468

469 Acknowledgments

We thank the North Temperate Lakes and Lake Mendota Microbial Observatory field

471

472

473

474

475

476

477

478

479

480

481

482

483

484 crews, UW-Trout Lake Station, the UW Center for Limnology, and the Global Lakes Ecological

Observatory Network for field and logistical support. We acknowledge efforts by many McMahon laboratory undergraduate students and technicians whose work has been related to sample collection and DNA extraction. We thank Emily Stanley and Joshua Hamilton for insightful comments on an early draft of this manuscript. Finally, we personally thank the individual program directors and leadership at the National Science Foundation for their commitment to continued support of long-term ecological research.

\section{References}

Anantharaman K., Brown CT., Hug LA., Sharon I., Castelle CJ., Probst AJ., Thomas BC., Singh A., Wilkins MJ., Karaoz U., Brodie EL., Williams KH., Hubbard SS., Banfield JF. 2016. Thousands of microbial genomes shed light on interconnected biogeochemical processes in an aquifer system. Nature Communications 7:1-11. DOI: 10.1038/ncomms13219.

Auman AJ., Stolyar S., Costello AM., Lidstrom ME. 2000. Molecular characterization of methanotrophic isolates from freshwater lake sediment. Applied and environmental 
485

486

487

488

489

490

491

492

493

494

495

496

497

498

499

500

501

502

503

504

505

506

507

508

509

510

511

512

513

514

515

516

517

518

519

520

521

522

523

524

525

526

527

528

529

530

microbiology 66:5259-66. DOI: 10.1128/AEM.66.12.5259-5266.2000.

Bendall ML., Stevens SL., Chan L-K., Malfatti S., Schwientek P., Tremblay J., Schackwitz W., Martin J., Pati A., Bushnell B., Froula J., Kang D., Tringe SG., Bertilsson S., Moran MA., Shade A., Newton RJ., McMahon KD., Malmstrom RR. 2016. Genome-wide selective sweeps and gene-specific sweeps in natural bacterial populations. The ISME Journal 10:1589-1601. DOI: 10.1038/ismej.2015.241.

Beversdorf LJ., Chaston SD., Miller TR., McMahon KD. 2015. Microcystin mcyA and mcyE gene abundances are not appropriate indicators of microcystin concentrations in lakes. PLOS ONE 10:1-18. DOI: 10.1371/journal.pone.0125353.

Beversdorf LJ., Miller TR., McMahon KD. 2013. The Role of Nitrogen Fixation in Cyanobacterial Bloom Toxicity in a Temperate, Eutrophic Lake. PLOS ONE 8:1-11. DOI: 10.1371/journal.pone.0056103.

Boden R., Hutt LP., Rae AW. 2017. Reclassification of Thiobacillus aquaesulis (Wood \& Kelly, 1995) as Annwoodia aquaesulis gen. nov., comb. nov., transfer of Thiobacillus (Beijerinck, 1904) from the Hydrogenophilales to the Nitrosomonadales, proposal of Hydrogenophilalia class. nov. withi. International Journal of Systematic and Evolutionary Microbiology 67:1191-1205. DOI: 10.1099/ijsem.0.001927.

Boisvert S., Raymond F., Godzaridis É., Laviolette F., Corbeil J. 2012. Ray Meta: scalable de novo metagenome assembly and profiling. Genome Biology 13:1-13. DOI: 10.1186/gb2012-13-12-r122.

Bowers RM., Kyrpides NC., Stepanauskas R., Harmon-Smith M., Doud D., Reddy TBK., Schulz F., Jarett J., Rivers AR., Eloe-Fadrosh EA., Tringe SG., Ivanova NN., Copeland A., Clum A., Becraft ED., Malmstrom RR., Birren B., Podar M., Bork P., Weinstock GM., Garrity GM., Dodsworth JA., Yooseph S., Sutton G., Glöckner FO., Gilbert JA., Nelson WC., Hallam SJ., Jungbluth SP., Ettema TJG., Tighe S., Konstantinidis KT., Liu WT., Baker BJ., Rattei T., Eisen JA., Hedlund B., McMahon KD., Fierer N., Knight R., Finn R., Cochrane G., Karsch-Mizrachi I., Tyson GW., Rinke C., Lapidus A., Meyer F., Yilmaz P., Parks DH., Eren AM., Schriml L., Banfield JF., Hugenholtz P., Woyke T. 2017. Minimum information about a single amplified genome (MISAG) and a metagenome-assembled genome (MIMAG) of bacteria and archaea. Nature Biotechnology 35:725-731. DOI: 10.1038/nbt.3893.

Bowles MW., Mogollon JM., Kasten S., Zabel M., Hinrichs K-U. 2014. Global rates of marine sulfate reduction and implications for sub-sea-floor metabolic activities. Science Express Reports. DOI: 10.1038/35351.

Bowman JP., Sly LI., Stackebrandt E. 1995. The phylogenetic position of the family Methylococcaceae. International Journal of Systematic Bacteriology 45:182-5. DOI: 10.1099/00207713-45-3-622a.

Al Bulushi I., Poole S., Deeth HC., Dykes GA. 2009. Biogenic amines in fish: Roles in intoxication, spoilage, and nitrosamine formation-A review. Critical Reviews in Food Science and Nutrition 49:369-377. DOI: 10.1080/10408390802067514.

Butman D., Stackpoole S., Stets E., McDonald CP., Clow DW., Striegl RG. 2015. Aquatic carbon cycling in the conterminous United States and implications for terrestrial carbon accounting. Proceedings of the National Academy of Sciences:1-6. DOI: 10.1073/pnas.1512651112.

Cabello-Yeves PJ., Zemskaya TI., Rosselli R., Coutinho FH., Zakharenko AS., Blinov V V., Rodriguez-Valera F., Drake HL. 2018. Genomes of Novel Microbial Lineages Assembled 
531

532

533

534

535

536

537

538

539

540

541

542

543

544

545

546

547

548

549

550

551

552

553

554

555

556

557

558

559

560

561

562

563

564

565

566

567

568

569

570

571

572

573

574

575

576

from the Sub-Ice Waters of Lake Baikal ENVIRONMENTAL MICROBIOLOGY crossm Downloaded from.

Camacho C., Coulouris G., Avagyan V., Ma N., Papadopoulos J., Bealer K., Madden TL. 2009. BLAST plus : architecture and applications. BMC Bioinformatics 10:1-9. DOI: Artn $421 \backslash$ nDoi 10.1186/1471-2105-10-421.

Caporaso JG., Lauber CL., Walters WA., Berg-Lyons D., Huntley J., Fierer N., Owens SM., Betley J., Fraser L., Bauer M., Gormley N., Gilbert JA., Smith G., Knight R. 2012. Ultrahigh-throughput microbial community analysis on the Illumina HiSeq and MiSeq platforms. The ISME Journal 6:1621-1624. DOI: 10.1038/ismej.2012.8.

Chistoserdova L., Chen S-W., Lapidus A., Lidstrom ME. 2003. Methylotrophy in Methylobacterium extorquens AM1 from a genomic point of view. Journal of bacteriology 185:2980-7. DOI: 10.1128/JB.185.10.2980-2987.2003.

Cole JJ., Prairie YT., Caraco NF., McDowell WH., Tranvik LJ., Striegl RG., Duarte CM., Kortelainen P., Downing JA., Middelburg JJ., Melack J. 2007. Plumbing the Global Carbon Cycle: Integrating Inland Waters into the Terrestrial Carbon Budget. Ecosystems 10:172185. DOI: $10.1007 / \mathrm{s} 10021-006-9013-8$.

Darling AE., Jospin G., Lowe E., Matsen FA., Bik HM., Eisen JA. 2014. PhyloSift: phylogenetic analysis of genomes and metagenomes. PeerJ 2:e243. DOI: 10.7717/peerj.243.

DeSantis TZ., Hugenholtz P., Larsen N., Rojas M., Brodie EL., Keller K., Huber T., Dalevi D., Hu P., Andersen GL. 2006. Greengenes, a chimera-checked 16S rRNA gene database and workbench compatible with ARB. Applied and Environmental Microbiology 72:5069-5072. DOI: 10.1128/AEM.03006-05.

Eiler A., Bertilsson S. 2004. Composition of freshwater bacterial communities associated with cyanobacterial blooms in four Swedish lakes. Environmental Microbiology 6:1228-1243. DOI: $10.1111 / \mathrm{j} .1462-2920.2004 .00657 . x$.

Eiler A., Langenheder S., Bertilsson S., Tranvik LJ. 2003. Heterotrophic bacterial growth efficiency and community structure at different natural organic carbon concentrations. Applied and environmental microbiology 69:3701-9. DOI: 10.1128/AEM.69.7.37013709.2003.

Eiler A., Mondav R., Sinclair L., Fernandez-Vidal L., Scofield DG., Schwientek P., MartinezGarcia M., Torrents D., McMahon KD., Andersson SG., Stepanauskas R., Woyke T., Bertilsson S. 2016. Tuning fresh: radiation through rewiring of central metabolism in streamlined bacteria. The ISME Journal 10:1902-1914. DOI: 10.1038/ismej.2015.260.

Engelbrektson AL., Kunin V., Wrighton KC., Zvenigorodsky N., Chen F., Ochman H., Hugenholtz P. 2010. Experimental factors affecting PCR-based estimates of microbial species richness and evenness. The ISME Journal 4:642.

Ghylin TW., Garcia SL., Moya F., Oyserman BO., Schwientek P., Forest KT., Mutschler J., Dwulit-Smith J., Chan L-K., Martinez-Garcia M., Sczyrba A., Stepanauskas R., Grossart HP., Woyke T., Warnecke F., Malmstrom R., Bertilsson S., McMahon KD. 2014. Comparative single-cell genomics reveals potential ecological niches for the freshwater acI Actinobacteria lineage. The ISME Journal 8:2503-16. DOI: 10.1038/ismej.2014.135.

Giroldo D., Augusto A., Vieira H. 2005. Polymeric and free sugars released by three phytoplanktonic species from a freshwater tropical eutrophic reservoir. Journal of Plankton Research 27:695-705. DOI: 10.1093/plankt/fbi043.

Gong X., Garcia-Robledo E., Revsbech N-P., Schramm A. 2018. Gene Expression of Terminal Oxidases in Two Marine Bacterial Strains Exposed to Nanomolar Oxygen Concentrations. 
577

578

579

580

581

582

583

584

585

586

587

588

589

590

591

592

593

594

595

596

597

598

599

600

601

602

603

604

605

606

607

608

609

610

611

612

613

614

615

616

617

618

619

620

621

622

FEMS Microbiology Ecology. DOI: 10.1093/femsec/fiy072/4983120.

Guillemette F., del Giorgio PA. 2011. Reconstructing the various facets of dissolved organic carbon bioavailability in freshwater ecosystems. Limnology and Oceanography 56:734748. DOI: 10.4319/lo.2011.56.2.0734.

Hahn MW., Scheuerl T., Jezberová J., Koll U., Jezbera J., Šimek K., Vannini C., Petroni G., Wu QL. 2012. The Passive Yet Successful Way of Planktonic Life: Genomic and Experimental Analysis of the Ecology of a Free-Living Polynucleobacter Population. PLoS ONE 7:e32772. DOI: 10.1371/journal.pone.0032772.

Hall MW., Rohwer RR., Perrie J., McMahon KD., Beiko RG. 2017. Ananke: temporal clustering reveals ecological dynamics of microbial communities. PeerJ 5:e3812. DOI: 10.7717/peerj.3812.

Hamilton JJ., Garcia SL., Brown BS., Oyserman BO., Moya-Flores F., Bertilsson S., Malmstrom RR., Forest KT., McMahon KD. 2017. Metabolic Network Analysis and Metatranscriptomics Reveal Auxotrophies and Nutrient Sources of the Cosmopolitan Freshwater Microbial Lineage acI. mSystems 2:e0091-17. DOI: 10.1128/mSystems.0009117.

Hanson TE., Tabita FR. 2001. A ribulose-1,5-bisphosphate carboxylase/oxygenase (RubisCO)like protein from Chlorobium tepidum that is involved with sulfur metabolism and the response to oxidative stress. Proceedings of the National Academy of Sciences 98:43974402. DOI: 10.1073/pnas.081610398.

He S., Stevens SLR., Chan L-K., Bertilsson S., Glavina Del Rio T., Tringe SG., Malmstrom RR., McMahon KD. 2017. Ecophysiology of Freshwater Verrucomicrobia Inferred from Metagenome-Assembled Genomes. mSphere 2:e00277-17. DOI: 10.1128/mSphere.0027717.

Henrissat B., Davies G. 1997. Structural and sequence-based classification of glycoside hydrolases. Current Opinion in Structural Biology 7:637-644. DOI: 10.1016/S0959440X(97)80072-3.

Holkenbrink C., Barbas SO., Mellerup A., Otaki H., Frigaard NU. 2011. Sulfur globule oxidation in green sulfur bacteria is dependent on the dissimilatory sulfite reductase system. Microbiology 157:1229-1239. DOI: 10.1099/mic.0.044669-0.

Hyatt D., Chen GL., LoCascio PF., Land ML., Larimer FW., Hauser LJ. 2010. Prodigal: Prokaryotic gene recognition and translation initiation site identification. $B M C$ Bioinformatics 11. DOI: 10.1186/1471-2105-11-119.

Igarashi K., Kashiwagi K. 1999. Polyamine transport in bacteria and yeast. Biochem. J. 344:633642.

Jonsson A., Meili M., Bergström A-K., Jansson M. 2001. Whole-lake mineralization of allochthonous and autochthonous organic carbon in a large humic lake (örträsket, N. Sweden). Limnology and Oceanography 46:1691-1700. DOI: 10.4319/lo.2001.46.7.1691.

Kalyuzhnaya MG., Beck DAC., Vorobev A., Smalley N., Kunkel DD., Lidstrom ME., Chistoserdova L. 2011. Novel methylotrophic isolates from lake sediment, description of Methylotenera versatilis sp. nov. and emended description of the genus methylotenera. International Journal of Systematic and Evolutionary Microbiology 62:106-111. DOI: 10.1099/ijs.0.029165-0.

Kanao T., Kawamura M., Fukui T., Atomi H., Imanaka T. 2002. Characterization of isocitrate dehydrogenase from the green sulfur bacterium chlorobium limicola: A carbon dioxidefixing enzyme in the reductive tricarboxylic acid cycle. European Journal of Biochemistry 
623

624

625

626

627

628

629

630

631

632

633

634

635

636

637

638

639

640

641

642

643

644

645

646

647

648

649

650

651

652

653

654

655

656

657

658

659

660

661

662

663

664

665

666

667

668

269:1926-1931. DOI: 10.1046/j.1432-1327.2002.02849.x.

Kane SR., Chakicherla AY., G Chain PS., Schmidt R., Shin MW., Legler TC., Scow KM., Larimer FW., Lucas SM., Richardson PM., Hristova KR., Livermore Na- L. 2007. WholeGenome Analysis of the Methyl tert-Butyl Ether-Degrading Beta-Proteobacterium Methylibium petroleiphilum PM1. JOURNAL OF BACTERIOLOGY 189:1931-1945. DOI: 10.1128/JB.01259-06.

Kang DD., Froula J., Egan R., Wang Z. 2015. MetaBAT, an efficient tool for accurately reconstructing single genomes from complex microbial communities. PeerJ 3:e1165. DOI: 10.7717/peerj.1165.

Karhunen J., Arvola L., Peura S., Tiirola M. 2013. Green sulphur bacteria as a component of the photosynthetic plankton community in small dimictic humic lakes with an anoxic hypolimnion. Aquatic Microbial Ecology 68:267-272. DOI: 10.3354/ame01620.

Kritzberg ES., Cole JJ., Pace ML., Granéli W., Bade DL. 2004. Autochthonous versus allochthonous carbon sources of bacteria: Results from whole-lake ${ }^{13} \mathrm{C}$ addition experiments. Limnology and Oceanography 49:588-596. DOI: 10.4319/lo.2004.49.2.0588.

Li H., Durbin R. 2010. Fast and accurate long-read alignment with Burrows-Wheeler transform. Bioinformatics 26:589-595. DOI: 10.1093/bioinformatics/btp698.

Linz AM., Crary BC., Shade A., Owens S., Gilbert JA., Knight R., McMahon KD. 2017. Bacterial Community Composition and Dynamics Spanning Five Years in Freshwater Bog Lakes. mSphere 2:1-15. DOI: e00169-17.

Luo R., Liu B., Xie Y., Li Z., Huang W., Yuan J., He G., Chen Y., Pan Q., Liu Y., Tang J., Wu G., Zhang H., Shi Y., Liu Y., Yu C., Wang B., Lu Y., Han C., Cheung DW., Yiu S-M., Peng S., Xiaoqian Z., Liu G., Liao X., Li Y., Yang H., Wang J., Lam T-W., Wang J. 2012. SOAPdenovo2: an empirically improved memory-efficient short-read de novo assembler. GigaScience 1:1-6. DOI: 10.1186/2047-217X-1-18.

Magooc T., Salzberg SL. 2011. FLASH: Fast length adjustment of short reads to improve genome assemblies. Bioinformatics 27:2957-2963. DOI: 10.1093/bioinformatics/btr507.

Markowitz VM., Chen IMA., Palaniappan K., Chu K., Szeto E., Grechkin Y., Ratner A., Jacob B., Huang J., Williams P., Huntemann M., Anderson I., Mavromatis K., Ivanova NN., Kyrpides NC. 2012. IMG: The integrated microbial genomes database and comparative analysis system. Nucleic Acids Research 40:115-122. DOI: 10.1093/nar/gkr1044.

Martinez-Garcia M., Brazel DM., Swan BK., Arnosti C., Chain PSG., Reitenga KG., Xie G., Poulton NJ., Gomez ML., Masland DED., Thompson B., Bellows WK., Ziervogel K., Lo CC., Ahmed S., Gleasner CD., Detter CJ., Stepanauskas R. 2012a. Capturing Single Cell Genomes of Active Polysaccharide Degraders: An Unexpected Contribution of Verrucomicrobia. PLoS ONE 7:e35314. DOI: 10.1371/journal.pone.0035314.

Martinez-Garcia M., Swan BK., Poulton NJ., Gomez ML., Masland D., Sieracki ME., Stepanauskas R. 2012b. High-throughput single-cell sequencing identifies photoheterotrophs and chemoautotrophs in freshwater bacterioplankton. The ISME Journal 6:113-123. DOI: 10.1038/ismej.2011.84.

Mou X., Vila-Costa M., Sun S., Zhao W., Sharma S., Moran MA. 2011. Metatranscriptomic signature of exogenous polyamine utilization by coastal bacterioplankton. Environmental Microbiology 3:798-806. DOI: 10.1111/j.1758-2229.2011.00289.x.

Newton RJ., Jones SE., Eiler A., McMahon KD., Bertilsson S. 2011. A guide to the natural history of freshwater lake bacteria. Microbiology and Molecular Biology Reviews 75:14-49. DOI: 10.1128/MMBR.00028-10. 
669 Parks DH., Imelfort M., Skennerton CT., Hugenholtz P., Tyson GW. 2015. CheckM: assessing

670

671

672

673

674

675

676

677

678

679

680

681

682

683

684

685

686

687

688

689

690

691

692

693

694

695

696

697

698

699

700

701

702

703

704

705

706

707

708

709

710

711

712

713

714 the quality of microbial genomes recovered from isolates, single cells, and metagenomes. Genome Research 25:1043-1055.

Paver SF., Kent AD. 2017. Temporal Patterns in Glycolate-Utilizing Bacterial Community Composition Correlate with Phytoplankton Population Dynamics in Humic Lakes. Microbial Ecology 60:406-418. DOI: 10.1007/S00248-0.

Peters JW., Schut GJ., Boyd ES., Mulder DW., Shepard EM., Broderick JB., King PW., Adams MWW. 2015. [FeFe]- and [NiFe]-hydrogenase diversity, mechanism, and maturation. Biochimica et Biophysica Acta - Molecular Cell Research 1853:1350-1369. DOI: 10.1016/j.bbamcr.2014.11.021.

Peura S., Eiler A., Bertilsson S., Nykänen H., Tiirola M., Jones RI. 2012. Distinct and diverse anaerobic bacterial communities in boreal lakes dominated by candidate division OD1. The ISME journal 6:1640-52. DOI: 10.1038/ismej.2012.21.

Peura S., Sinclair L., Bertilsson S., Eiler A. 2015. Metagenomic insights into strategies of aerobic and anaerobic carbon and nitrogen transformation in boreal lakes. Scientific Reports 5:12102. DOI: 10.1038/srep12102.

Price MN., Dehal PS., Arkin AP. 2010. FastTree 2 - Approximately maximum-likelihood trees for large alignments. PLOS ONE 5. DOI: 10.1371/journal.pone.0009490.

Ramachandran A., Walsh DA. 2015. Investigation of XoxF methanol dehydrogenases reveals new methylotrophic bacteria in pelagic marine and freshwater ecosystems. FEMS Microbiology Ecology 91:fiv105. DOI: 10.1093/femsec/fiv105.

Ramanan R., Kim B-H., Cho D-H., Oh H-M., Kim H-S. 2015. Algae-bacteria interactions: evolution, ecology and emerging applications. Biotechnology Advances. DOI: 10.1016/j.biotechadv.2015.12.003.

Rinke C., Schwientek P., Sczyrba A., Ivanova NN., Anderson IJ., Cheng J-F., Darling AE., Malfatti S., Swan BK., Gies E a., Dodsworth J a., Hedlund BP., Tsiamis G., Sievert SM., Liu W-T., Eisen J a., Hallam SJ., Kyrpides NC., Stepanauskas R., Rubin EM., Hugenholtz P., Woyke T. 2013. Insights into the phylogeny and coding potential of microbial dark matter. Nature 499:431-437. DOI: 10.1038/nature12352.

Rognes T., Flouri T., Nichols B., Quince C., Mahé F. 2016. VSEARCH: a versatile open source tool for metagenomics. PeerJ 4:1-18. DOI: 10.7717/peerj.2584.

Rohwer RR., Hamilton JJ., Newton RJ., McMahon KD. 2018. TaxAss: Leveraging a Custom Freshwater Database Achieves Fine-Scale Taxonomic Resolution. mSphere 3. DOI: 10.1128/mSphere.00327-18.

Roux S., Chan LK., Egan R., Malmstrom RR., McMahon KD., Sullivan MB. 2017. Ecogenomics of virophages and their giant virus hosts assessed through time series metagenomics. Nature Communications 8. DOI: 10.1038/s41467-017-01086-2.

Salcher MM., Neuenschwander SM., Posch T., Pernthaler J. 2015. The ecology of pelagic freshwater methylotrophs assessed by a high-resolution monitoring and isolation campaign. The ISME Journal 9:2442-2453. DOI: 10.1038/ismej.2015.55.

Salcher MM., Posch T., Pernthaler J. 2013. In situ substrate preferences of abundant bacterioplankton populations in a prealpine freshwater lake. The ISME Journal 7:896-907. DOI: $10.1038 /$ ismej.2012.162.

Schloss PD., Westcott SL., Ryabin T., Hall JR., Hartmann M., Hollister EB., Lesniewski RA., Oakley BB., Parks DH., Robinson CJ., Sahl JW., Stres B., Thallinger GG., Van Horn DJ., Weber CF. 2009. Introducing mothur: Open-source, platform-independent, community- 
715 supported software for describing and comparing microbial communities. Applied and

716 Environmental Microbiology 75:7537-7541. DOI: 10.1128/AEM.01541-09.

717

718

719

722

723

724

725

726

727

728

729

730

731

732

733

734

735

736

737

738

739

740

Seitzinger S., Harrison JA., Böhlke JK., Bouwman AF., Lowrance R., Peterson B., Tobias C., Drecht G Van. 2006. DENITRIFICATION ACROSS LANDSCAPES AND WATERSCAPES: A SYNTHESIS. Ecological Applications 16:2064-2090. DOI: 10.1890/1051-0761(2006)016[2064:DALAWA]2.0.CO;2.

Shade A., Kent AD., Jones SE., Newton RJ., Triplett EW., McMahon KD. 2007. Interannual dynamics and phenology of bacterial communities in a eutrophic lake. Limnology and Oceanography 52:487-494. DOI: 10.4319/lo.2007.52.2.0487.

Smith VH. 2003. Eutrophication of freshwater and coastal marine ecosystems a global problem. Environmental Science and Pollution Research 10:126-139. DOI: 10.1065/espr2002.12.142.

Sommer DD., Delcher AL., Salzberg SL., Pop M. 2007. Minimus: a fast, lightweight genome assembler. BMC Bioinformatics 8:64. DOI: 10.1186/1471-2105-8-64.

Tang KH., Blankenship RE. 2010. Both forward and reverse TCA cycles operate in green sulfur bacteria. Journal of Biological Chemistry 285:35848-35854. DOI: 10.1074/jbc.M110.157834.

Varghese NJ., Mukherjee S., Ivanova N., Konstantinidis KT., Mavrommatis K., Kyrpides NC., Pati A. 2015. Microbial species delineation using whole genome sequences. Nucleic Acids Research 43:gkv657-. DOI: 10.1093/nar/gkv657.

Williamson CE., Dodds W., Kratz TK., Palmer MA. 2008. Lakes and streams as sentinels of environmental change in terrestrial and atmospheric processes. Frontiers in Ecology and the Environment 6:247-254. DOI: 10.1890/070140.

Zhang H., Yohe T., Huang L., Entwistle S., Wu P., Yang Z., Busk PK., Xu Y., Yin Y. 2018. dbCAN2: a meta server for automated carbohydrate-active enzyme annotation. Nucleic Acids Research 46:W95-W101. DOI: 10.1093/nar/gky418. 


\section{Table $\mathbf{1}$ (on next page)}

Characteristics of Lake Mendota and Trout Bog Lake.

Water from Lake Mendota and Trout Bog was sampled weekly during the ice-free periods using an integrated water column sampler and bacteria were collected on a 0.22 micron filter. Metagenomic sequencing was performed on DNA extracted from filters collected in 2008-2012 from Lake Mendota and in 2007-2009 from Trout Bog. The epilimnion (upper thermal layer) was sampled in both lakes, while the hypolimnion (bottom thermal layer) was sampled only in Trout Bog. Chemistry data were collected by NTL-LTER from depth discrete samples taken from 0 and $4 \mathrm{~m}$ for Lake Mendota, $0 \mathrm{~m}$ for the Trout Bog Epilimnion, and 3 and $7 \mathrm{~m}$ for the Trout Bog Hypolimnion. Values reported here are the means of all measurements in the sampling time span for each lake, with standard deviations reported in parentheses. 


\begin{tabular}{ccc} 
Lake Mendota & $\begin{array}{c}\text { Trout Bog } \\
\text { Epilimnion }\end{array}$ & $\begin{array}{c}\text { Trout Bog } \\
\text { Hypolimnion }\end{array}$ \\
\hline
\end{tabular}

\begin{tabular}{|c|c|c|c|}
\hline \multirow{3}{*}{$\begin{array}{r}\text { Location } \\
\text { Coordinates }\end{array}$} & & \\
\hline & Madison, WI & \multicolumn{2}{|c|}{ Boulder Junction, WI } \\
\hline & $43.107055,-$ & \multicolumn{2}{|c|}{$46.041172,-89.686297$} \\
\hline Depth of lake (m) & 25.3 & \multicolumn{2}{|c|}{7.9} \\
\hline Surface area of lake $\left(\mathrm{km}^{2}\right)$ & 39.61 & \multicolumn{2}{|c|}{0.01} \\
\hline $\begin{array}{r}\text { Microbial sampling depth } \\
\text { range (m) }\end{array}$ & $0-12$ & $0-2$ & $2-7$ \\
\hline \multirow{2}{*}{$\begin{array}{r}\text { Years sampled } \\
\text { Oxygenation }\end{array}$} & $2008-2012$ & $2007-2009$ & $2007-2009$ \\
\hline & Oxic & Oxic & Suboxic/Anoxic \\
\hline $\mathbf{p H}$ & $8.6(0.4)$ & $5.0(0.2)$ & $5.3(0.2)$ \\
\hline \multirow{2}{*}{$\begin{array}{r}\text { Dissolved inorganic } \\
\text { carbon }(\mathrm{ppm}) \\
\text { Dissolved organic carbon } \\
(\mathrm{ppm})\end{array}$} & $41(5)$ & $2.6(2.2)$ & $6.9(3.1)$ \\
\hline & $6.0(6.2)$ & $18(5)$ & $22(6)$ \\
\hline $\begin{array}{r}\text { Total dissolved nitrogen } \\
(\mathbf{p p b})\end{array}$ & $923(487)$ & $637(204)$ & $1392(1031)$ \\
\hline \multirow{2}{*}{$\begin{array}{r}\text { Total nitrogen (ppb) } \\
\text { Total dissolved } \\
\text { phosphorus (ppb) }\end{array}$} & $1099(521)$ & $831(316)$ & $1684(1563)$ \\
\hline & $44(51)$ & $15(14)$ & $69(98)$ \\
\hline \multirow{2}{*}{$\begin{array}{r}\text { Total phosphorus (ppb) } \\
\text { Sulfate (ppm) }\end{array}$} & $64(52)$ & $32(14)$ & $95(126)$ \\
\hline & $17(1)$ & $1.2(0.3)$ & $0.9(0.7)$ \\
\hline
\end{tabular}




\section{Figure 1}

Analysis of marker gene abundances reveals differences between lakes and layers.

To assess potential differences in microbial metabolisms in our study sites, we predicted open reading frames in unassembled metagenomes using Prodigal and compared the resulting ORFs to a custom database of metabolic marker genes using BLAST. In these boxplots, significant differences in numbers of gene hits between sites was tested using a pairwise Wilcoxon rank sum test with a Bonferroni correction; significance was considered to be $p<0.05$. 94 metagenomes were tested for Mendota, while 47 metagenomes were tested in each layer of Trout Bog. Significant differences between the Trout Bog and Mendota epilimnia and between the Trout Bog epilimnion and hypolimnion are indicated by a green or a purple star, respectively. Significant differences between the Trout Bog hypolimnion and the Mendota epilimnion were not tested, as the large number of variables differing in these sites makes the comparison less informative. This analysis revealed differences in the number of marker genes observed by lake for many metabolic processes involved in carbon, nitrogen, and sulfur cycling. P-values of markers described in Figure 1 and elsewhere in the text are reported in Table S3. 


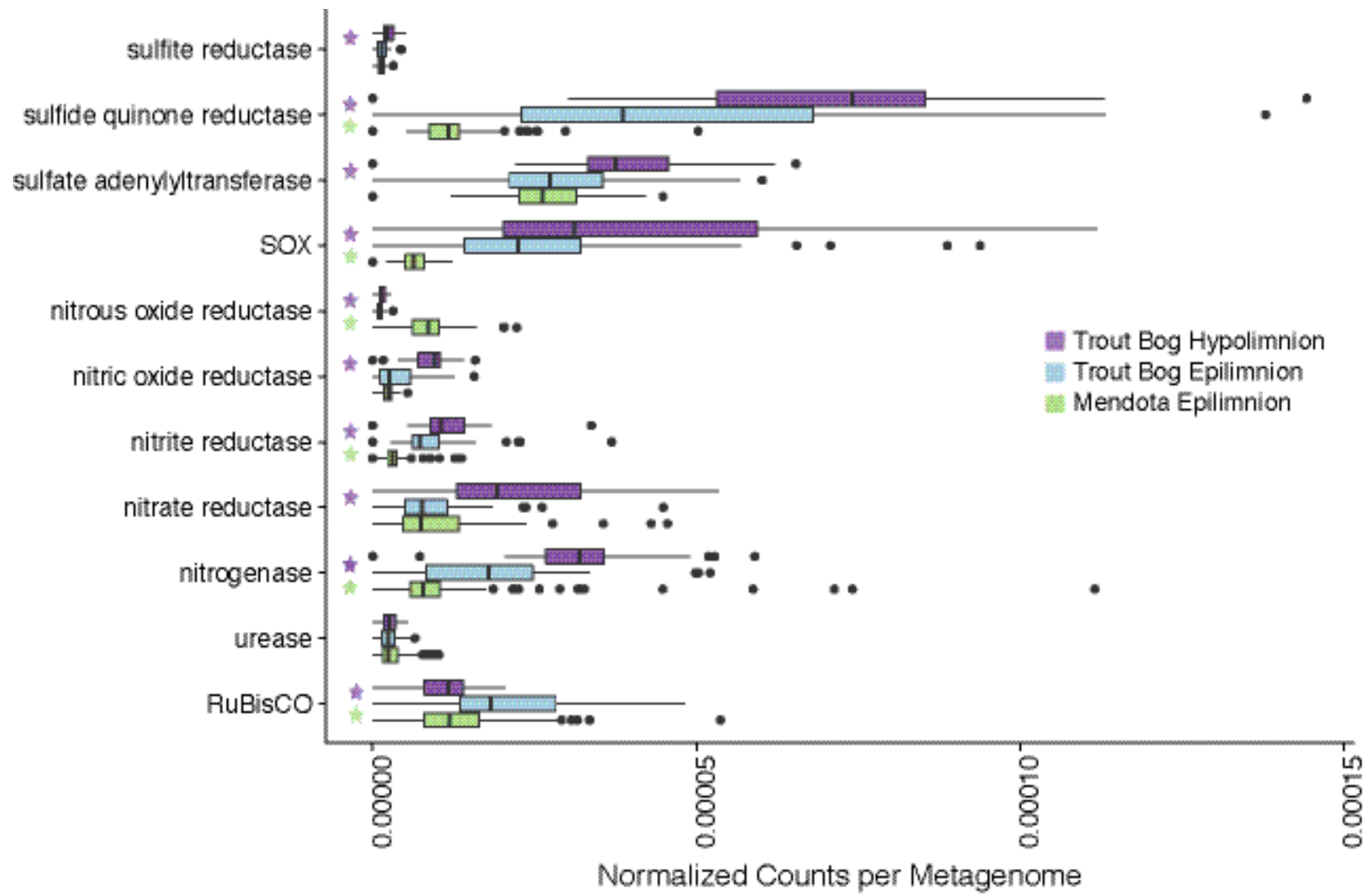




\section{Figure 2}

Metabolisms in Lake Mendota and Trout Bog Lake.

A pathway was considered present when at least $50 \%$ of enzymes in a pathway were encoded in the genome and all enzymes unique to or required for the pathway were present.

Putative pathway presence was aggregated by lake and phylum. This analysis can link potential functions identified in the metagenomes to taxonomic groups that may perform those functions. For example, MAGs that putatively fix carbon also likely fix nitrogen in both lakes. Similarly, putative degradation pathways for rhamnose, fucose, and galactose were frequently encoded within the same MAGs. Proteobacteria was split into classes due to the high diversity of this phylum. Data for each genome can be found in Data S6. 


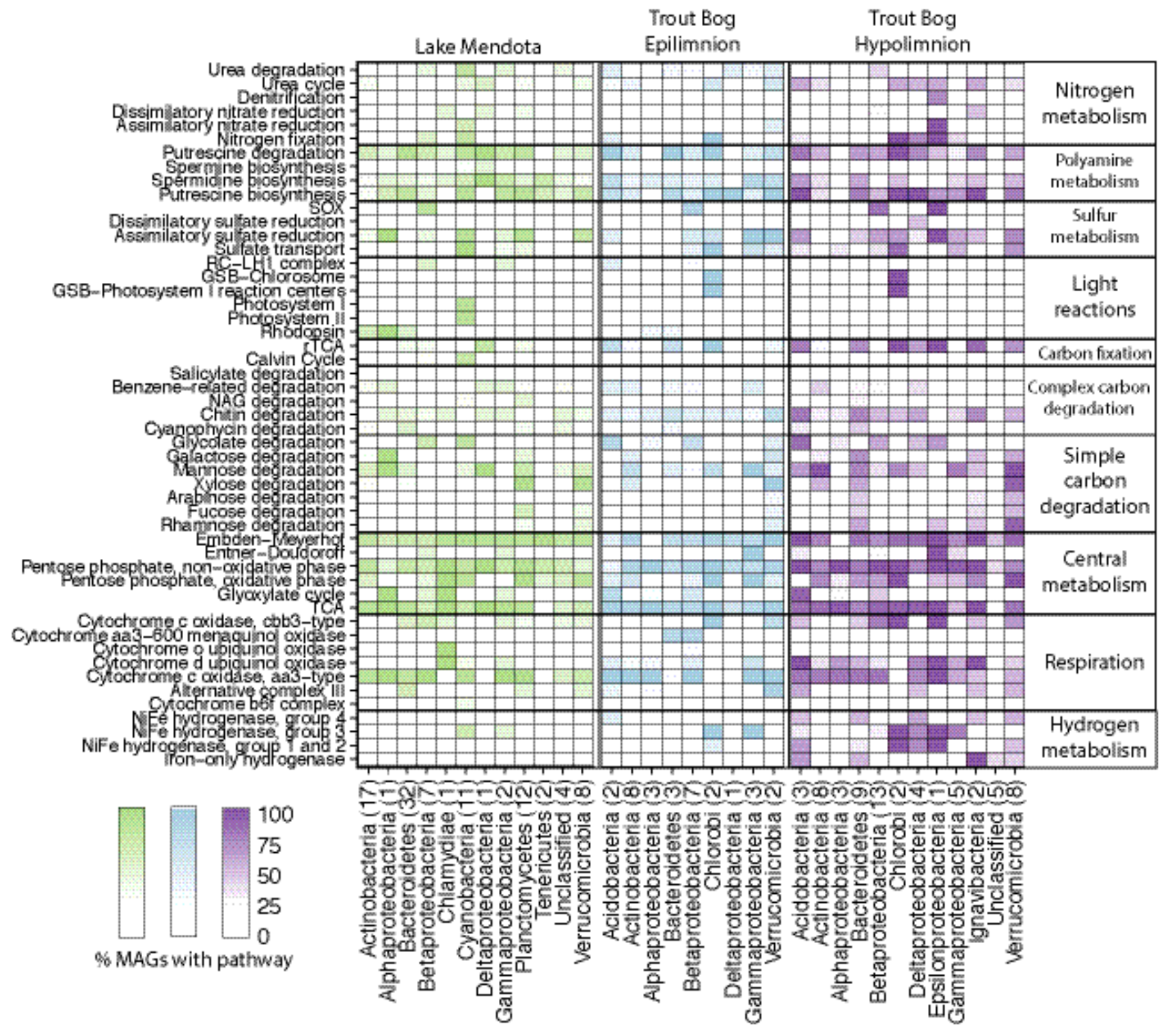


Figure 3

Glycoside hydrolase content in the MAGs.

Annotations of GHs were used as an indication of complex carbon degradation. Genes potentially encoding GHs were identified and assigned CAZyme annotations using dbCAN2. GH coding density was calculated for each MAG and averaged by order and lake. While a few orders contained genes encoding glycoside hydrolases in all three sites, many orders were unique to each site. The orders with the highest coding densities were all found in the Trout Bog hypolimnion. Glycoside hydrolase diversity, an indicator of the range of substrates an organism can degrade, was significantly correlated with coding density ( $r 2=0.92, p<$ $\left.2.2 \times 10^{-16}\right)$. Proteobacteria was split into classes due to the high diversity of this phylum.

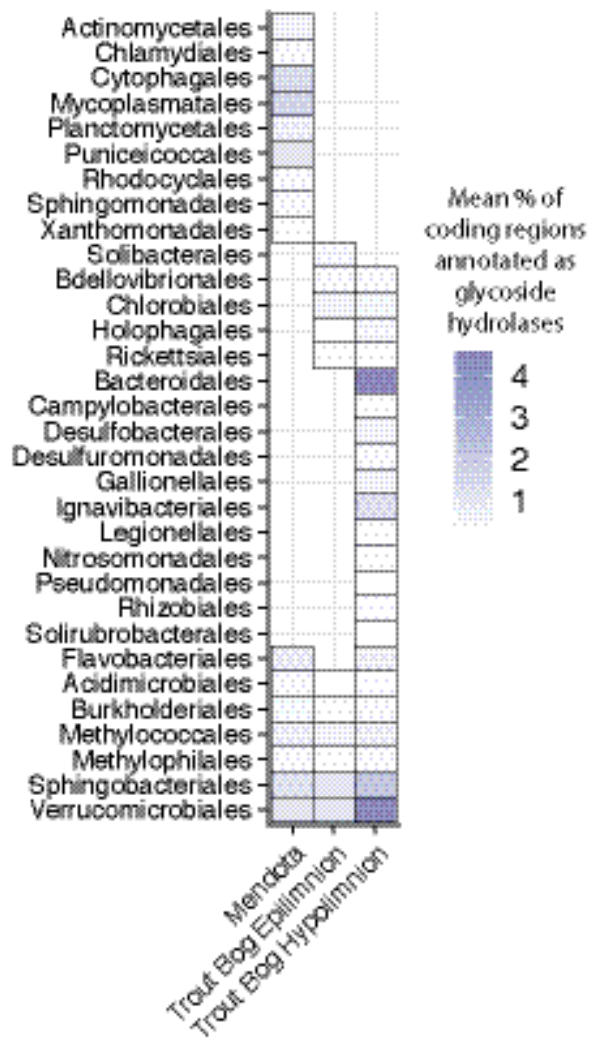




\section{Figure 4}

Cyanobacteria and nitrogen fixation over time.

To investigate potential functional changes over time in Mendota, we compared the abundances of Cyanobacteria MAGs (approximated using read coverage normalized by genome length) to the abundances of nitrogen fixation marker genes (approximated using the number of BLAST hits to metagenomes normalized by metagenome size). Only the most abundant Cyanobacteria MAG is shown for each year (panels A-E) because a single MAG was much more abundant than the rest in each year. The marker genes used were TIGR1282, TIGR1286, and TIGR1287, encoding subunits of Mo-Fe nitrogenase, as these were the most frequently observed nitrogenase markers in the Mendota metagenomes (panels F-J). Significantly correlated trends over time were observed between the MAGs and the nitrogenase marker genes in 2008, 2011, and 2012. In years where there was no significant correlation, the dominant MAG did not contain genes indicative of the nitrogen fixation pathway. This suggests that Cyanobacteria dynamics may be linked to the potential for nitrogen fixation in Mendota. 


\section{Cyanobacteria MAGs}

A

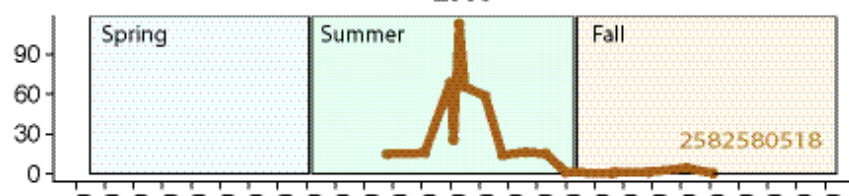

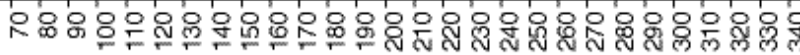

B

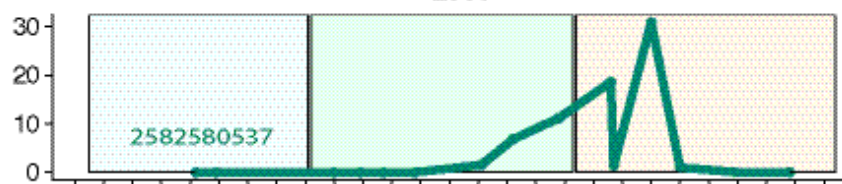

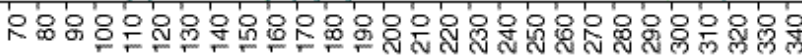
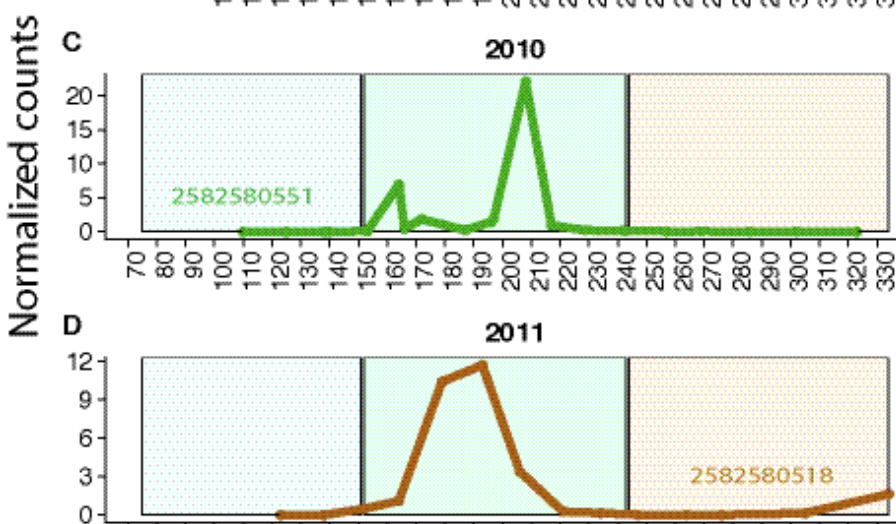

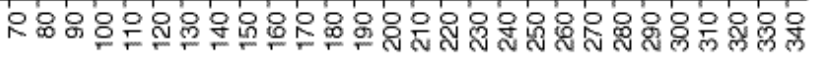

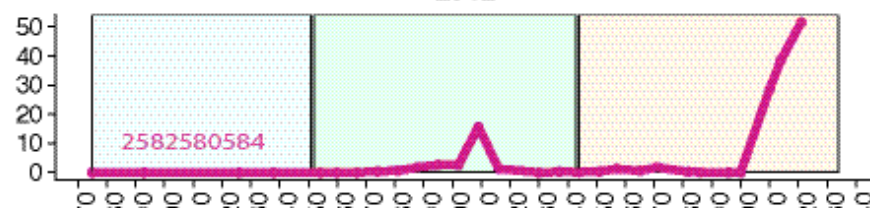

Nitrogenase Marker Genes

$\mathbf{F}$

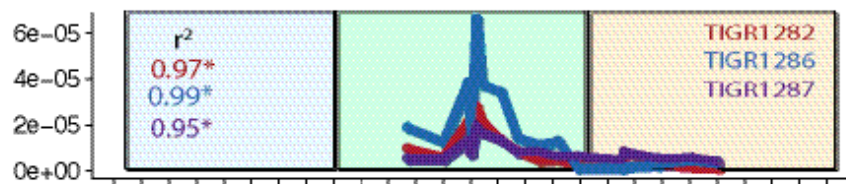

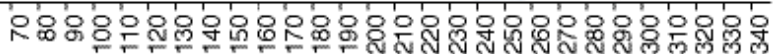

G

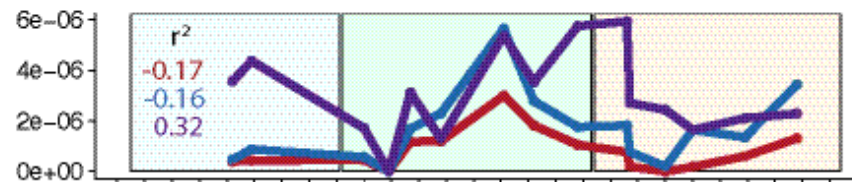

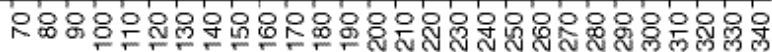

H

H

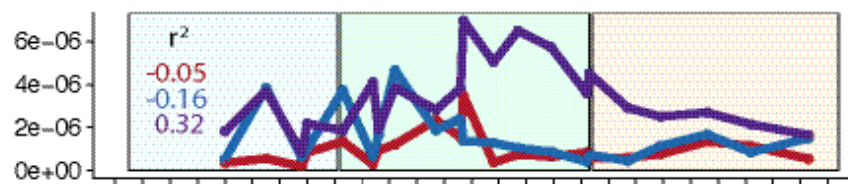

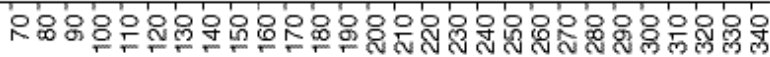

I

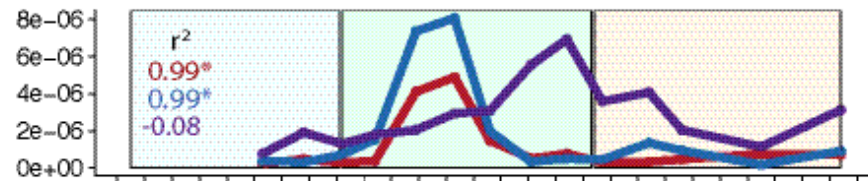

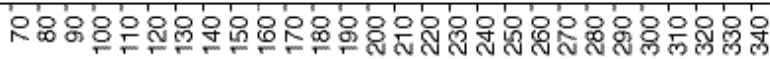

$\mathrm{J}$

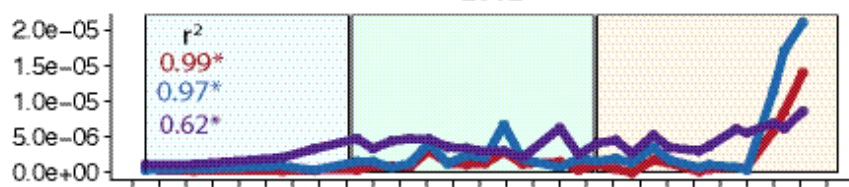

$0.00+00$

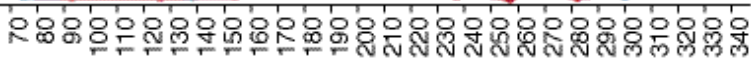

Julian Date 